\title{
Effects of a Province-Based Strategy to Prevent Suicide Using Charcoal Burning: A Preliminary Time Series Analysis
}

\author{
Sun-Jin Jo', Mi Kyung Yun², and Myung-Soo Lee ${ }^{2 \bowtie}$ \\ ${ }^{1}$ Department of Preventive Medicine, College of Medicine, The Catholic University of Korea, Seoul, Republic of Korea \\ ${ }^{2}$ Gyeonggi Provincial Suicide Prevention Center, Suwon, Republic of Korea
}

The suicide rate in Korea has been declining steadily after peaking in 2011. However, to date, time-series analyses of Korean suicide rate data have mainly addressed factors related to increases in suicide rates. This study analyzed one of the most important evidence-based public health strategies to decrease suicide, that is, preventive effects of restricting access to lethal means via a charcoal-selling procedure improvement campaign, using multivariate time series analysis. The results showed the campaign in Gyeonggi Province had a significant effect on decreasing the number of charcoal-burning suicides in this area. It is believed that the present study has important implications in terms of providing the first empirical evidence for the charcoal-selling procedure improvement campaign in Korea. Further repeated research is needed to evaluate the impact of the intervention when the more enough observational data become available.

Psychiatry Investig 2019;16(8):621-624

Key Words Suicide, Time series analysis, Charcoal burning, Restriction to means.

\section{INTRODUCTION}

The suicide rate in Korea has been declining steadily after a peak of 31.4 per 100,000 in 2011, reaching 26.5 in $2016 .{ }^{1}$ The suicide rate changed with increases and decreases in the unemployment rate until 2011. From 2013, however, the suicide rate decreased, even though the unemployment rate increased. ${ }^{1,2}$ The time when suicide rates began to decline is in line with the start of multi-faceted suicide prevention activities at central and local government levels in our society as a whole.

Time series analysis is a suitable method to analyze the impact of such suicide prevention activities on suicide rates. Nevertheless, to date, time-series analyses of Korean suicide rate data have mainly addressed factors related to increases in suicide rates, such as economic crises, media reports on celebrities' suicides, or unemployment. . $^{3-5}$

Received: July 19, 2018 Revised: November 11, 2018

Accepted: June 13, 2019

$\triangle$ Correspondence: Myung-Soo Lee, MD, MPH

Gyeonggi Provincial Suicide Prevention Center, 69 Suseong-ro 245beon-gil, Jangan-gu, Suwon 16316, Republic of Korea

Tel: +82-31-212-0435, Fax: +82-31-212-0442, E-mail: mslee1010@gmail.com

(c) This is an Open Access article distributed under the terms of the Creative Commons Attribution Non-Commercial License (https://creativecommons.org/licenses/by$\mathrm{nc} / 4.0$ ) which permits unrestricted non-commercial use, distribution, and reproduction in any medium, provided the original work is properly cited.
Meanwhile, studies on effects of interventions to prevent suicide show that restriction of access to lethal means is one of the most important evidence-based public health strategies to decrease suicide. ${ }^{6,7}$ As part of such strategy, Gyeonggi Province of Korea introduced a program of restriction of access to charcoal for the first time in this nation, and has gradually expanded its scope. Currently, the program is being implemented in all 31 municipalities, since $2017 .^{8}$

Since the charcoal-related suicide prevention program has not been in place for 10 years, there has not been enough data available to evaluate the long-term impact of the program on suicide rates. ${ }^{9}$ However, if a preliminary analysis shows that accessibility restrictions on charcoal are related to recent suicide rates in Gyeonggi Province, it would provide useful information when making decisions about whether to continue this intervention in the future.

Therefore, this study was performed to investigate whether the charcoal-selling procedure improvement campaign to restrict access to charcoal in Gyeonggi Province affected recent trends of suicide using charcoal.

\section{METHODS}

\section{Design}

In this study, the effect of the charcoal burning suicide pre- 
vention program was estimated using multivariate time series analysis, which is a statistical technique to test whether the effect of a particular event on the time series trend is significant if the observed time series does not change independently but is influenced by other time series. ${ }^{10}$

\section{Sample}

Time series data analyzed in the present study include the number of suicides by burning charcoal and the number of districts participating in the charcoal-selling procedure improvement campaign in Gyeonggi Province. Gyeonggi Province surrounds the capital city of South Korea, Seoul, and has the largest population among Korean metropolitan governments: its population is about 13 million, accounting for about $25 \%$ of the Korean population. ${ }^{11}$

Suicides by burning charcoal are defined as suicide according to code X67 of the tenth revision of the International Classification of Diseases codes (ICD-10), and we collected data on causes of death standardized by sex and age for each year from 2000 to 2016, released by the National Statistical Office. ${ }^{12,13}$ While the X67 code includes suicides due to car exhaust or nitrogen oxide gas poisoning, it is known that there is no problem in defining the X67 code as suicide using charcoal-burning. ${ }^{14}$ The number of repeated observations included in time series analysis met the conditions proposed by Janoski and Isaac. ${ }^{15}$

In this study, the number of suicides by charcoal burning in the Gyeonggi province was used without standardization by gender and age. The reason why the crude data was used is that the study did not compare suicide rates among the various regions but analyzed the annual suicide trends by charcoal burning in one region. Nonetheless, standardization might be needed to look at changes in the time series of suicide rates. However, since there was no significant change in the composition of sex and age group of Gyeonggi Province population during the period included in this data analysis, ${ }^{16}$ and the level of actual health problems in the real world was of interest in terms of mental health service planning, the data on the number of suicide using charcoal burning in Gyeonggi province were used without standardization.

The charcoal-selling procedure improvement campaign in Gyeonggi Province forms part of strategies that were initiated to prevent charcoal burning suicides in this area in 2014. Shops participating in this campaign changed the way they sell bomblets: they are kept out of sight, not on display, and they are taken out only when customers request them. This campaign allows sellers to detect someone who has suicidal intentions by asking about the use of charcoal, and if so, to provide an opportunity to reconsider any extreme decisions or to ask for professional help. In Gyeonggi Province, this campaign to re- strict access to lethal means, specifically, charcoal, has been gradually expanded from being implemented in single district in 2014, to ten districts in 2015, and to twenty-eight districts, except for three districts- G-si and N-si, and G-gun-, in $2016^{8}$

\section{Statistical analysis}

A multivariate regression model using ARIMA procedure was used to eliminate the autocorrelation problem, reflect the trends and noise of the time series data, and evaluate differences in the number of suicide deaths via charcoal burning according to the initiation and dissemination of the Gyeonggi Province-based intervention for the charcoal-selling procedure improvement campaign.

To adjust for the impact of the nation-wide suicide prevention strategy and overall decline in suicide rates from 20112016, we included two variables in the multivariate time series model: initiation and continuation of activities at the National Suicide Prevention Center of Korea and sex- and age-standardized suicide rates of Gyeonggi Province. ${ }^{13}$

A time series graph of the number of suicides by burning charcoal shows a trend that increased over time but began decreasing after a peak in 2014. These trends did not show a pattern based on the average reference line, so the data needed transformation to become stationary. When looking at the primary difference non-seasonal autocorrelation function (ACF) and partial autocorrelation function (PACF) of the number of suicides using charcoal-burning, the Box-Ljung statistic of all time lags had $\mathrm{p}>0.05(0.511-0.871)$ without a significant spike, indicating the time series data showed stationarity. Based on the autocorrelation and the partial correlation function, and the recommendation of the expert modeler module, the ARIMA $(0,1,0)$ model was found to be appropriate.

\section{RESULTS}

The number of suicide deaths in Korea during the past 10 years was 10,736 in 2006, 15,906 in 2011, and 13,092 in 2016. Among the suicide deaths in Korea, the proportion of suicide in Gyeonggi Province was 20.7\% (2,222 persons), 22.5\% (3,580 persons) and $22.0 \%$ (2,879 persons) in 2006, 2011, and 2017 , respectively. ${ }^{1}$

Characteristics of the time series data were as follows: by 2007 , burning charcoal accounted for less than $1 \%$ of all suicide methods. After Korean mainstream media widely publicized that a celebrity had committed suicide using charcoalburning in late 2007, the number of suicides using the same method increased from 2008. The number hit a record high of 536 suicides in 2014, exceeding 17\% of all suicides in 2014. 
The number of suicides using charcoal burning declined and dropped to 433 (15\%) in 2016 (Figure 1). That indicates a decrease of about $19 \%$ of suicides using charcoal burning. ${ }^{13}$ Details of the number and proportion of suicides caused by charcoal burning in Gyeonggi Province during the last 10 years were as follows: 18 (0.8\%) in 2006, 13 (0.5\%) in 2007; 73 (2.7\%) in 2008; $175(5.3 \%)$ in 2009; $187(5.5 \%)$ in 2010; $288(8.0 \%)$ in $2011 ; 294(9.1 \%)$ in $2012 ; 286(14.4 \%)$ in $2013 ; 536(17.1 \%)$ in $2014 ; 514(16.5 \%)$ in 2015; and $433(15.0 \%)$ in 2016. The only suicide method that fell more than $0.5 \%$ points from the total in 2014 was charcoal burning except for hanging (from $53.4 \%$ to $52.4 \%)^{13}$

A multivariate time series analysis was performed to analyze the effects of suicide prevention interventions in Gyeonggi Province on the number of suicides by burning charcoal. The results showed that the campaign to improve the charcoal-selling procedure was a significant intervention for reducing the number of suicides using charcoal $(\mathrm{t}=-2.482, \mathrm{p}=$ 0.029). Meanwhile, the initiation and activity of the Korea Suicide Prevention Center, one of the control variables, was mar- ginally significant $(\mathrm{t}=1.93, \mathrm{p}=0.078)$, and the other control variable, the suicide rate of Gyeonggi Province, was not significant $(\mathrm{t}=1.32, \mathrm{p}=0.210)$.

When residual analysis was conducted to determine the fitness of the model, no peak beyond the confidence limits at the ACF ( $r=-0.313-0.170)$ or PACF $(r=-0.313-0.004)$ of residual was observed, confirming the model was acceptable.

\section{DISCUSSION}

Restricting access to lethal means of suicide has been emphasized as a key approach in the evidence-based public health suicide prevention strategy. ${ }^{17}$ In particular, the effect of accessibility restrictions on charcoal has been repeatedly proven in Asian countries. ${ }^{6,7}$ In this context, the authors analyzed the effects of the campaign for charcoal-selling procedure improvement in a time series, showing that restricting access to lethal means could be effective in Korea.

The reason the results of this study should be taken seriously is that while the overall suicide rate of Gyeonggi Prov-

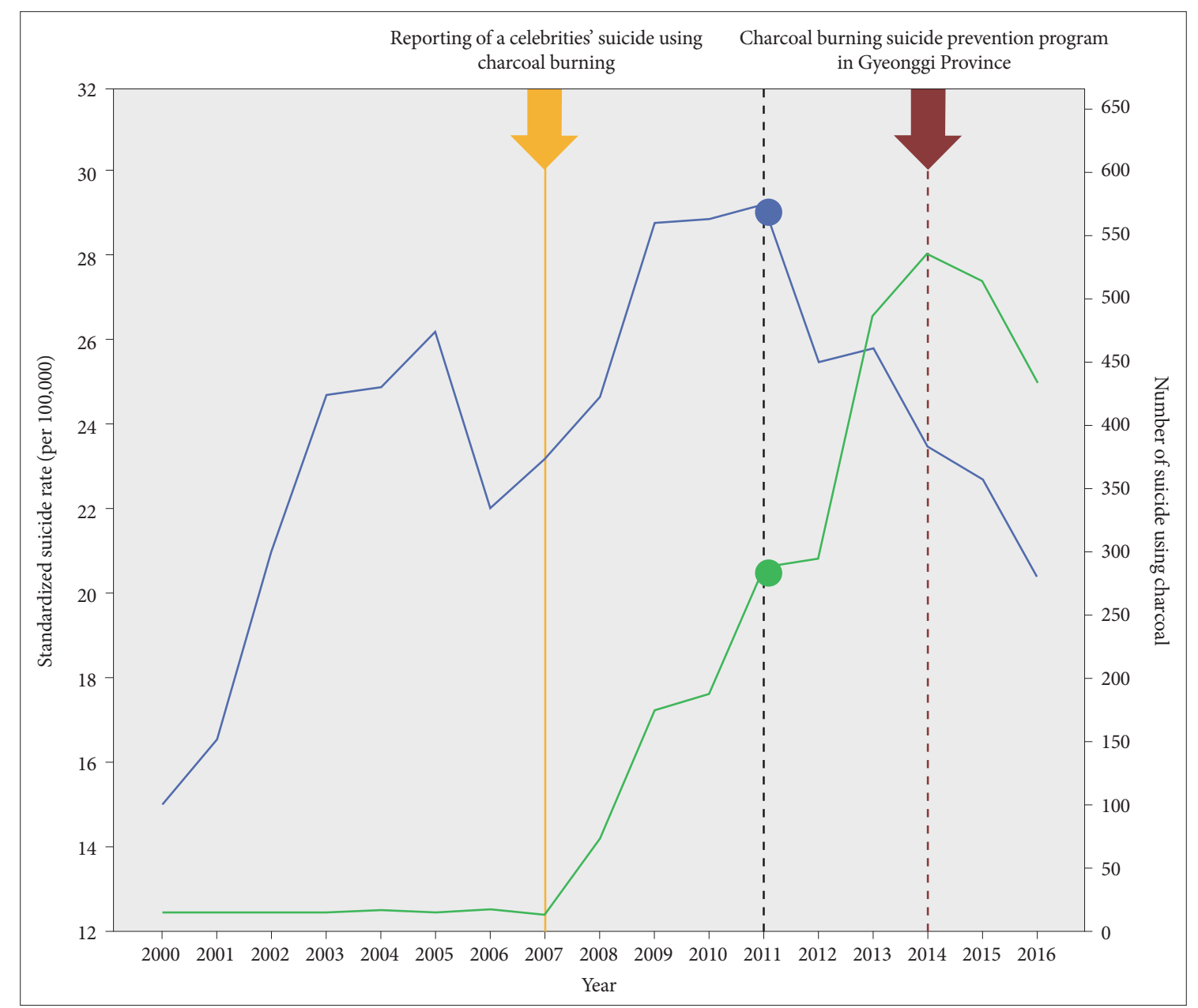

Figure 1. Standardized suicide rate and the number of suicide using charcoal burning in Gyeonggi Province (2000-2016). 
ince had been declining since 2011, the number of suicides by charcoal-burning had been gradually on the rise; the authors proved that the number of suicides by charcoal-burning started to decline after the public campaign was implemented in 2014. Moreover, the present results are considered reasonable, since interventions by the Korea Suicide Prevention center conducted throughout the country at the same time, and the decline in the suicide rate of Gyeonggi Province during the same period were adjusted for.

Considering that having debt problems, and a low level of contact with psychiatric services have been the main features of suicide victims using charcoal-burning, ${ }^{18,19}$ it is believed that the social support system of this province, such as identifying suicide-related risks early and addressing them appropriately through the charcoal-selling procedure improvement campaign, seems to be working.

The limitation of this study is that the data analyzed did not include a sufficient period of observation after the initiation of the public intervention, as opposed to 13 years before the intervention. However, we aimed to explore future directions of comprehensive suicide prevention strategies at the Province level, and provide information to decision makers in a timely manner. If we wait too long for a sufficient observation period to transpire, it might be too late to decide whether to continue the intervention or not. It is believed that the present study has important implications in terms of providing the first empirical evidence for the charcoal-selling procedure improvement campaign in Korea. Further repeated research is needed to evaluate the impact of the intervention when enough observational data is available.

\section{Acknowledgments}

This study was supported by a grant of the Korean Mental Health Technology R\&D Project, Ministry of Health \& Welfare, Republic of Korea (HM15C1112).

\section{Conflicts of Interest}

The authors have no potential conflicts of interest to disclose.

\section{Author Contributions}

Conceptualization: Myung-Soo Lee, Sun-Jin Jo. Data curation: Sun-Jin Jo, Mi Kyung Yun. Formal analysis: Sun-Jin Jo. Funding acquisition: MyungSoo Lee. Investigation: Sun-Jin Jo, Mi Kyung Yun, Myung-Soo Lee. Methodology: Sun-Jin Jo. Project administration: Mi Kyung Yun. Resources: Mi Kyung Yun, Myung-Soo Lee. Software: Sun-Jin Jo. Supervision: MyungSoo Lee. Validation: Sun-Jin Jo, Mi Kyung Yun. Visualization: Sun-Jin Jo. Writing_original draft: Sun-Jin Jo. Writing_review \& editing: Mi Kyung Yun, Myung-Soo Lee, Sun-Jin Jo.

\section{ORCID iDs}

$\begin{array}{ll}\text { Myung-Soo Lee } & \text { https://orcid.org/0000-0002-4201-7025 } \\ \text { Sun-Jin Jo } & \text { https://orcid.org/0000-0002-8465-9632 }\end{array}$

\section{REFERENCES}

1. Korean Statistical Information Service. Cause of Death, Annual 20112016. Available at: http://kosis.kr/eng/statisticsList/statisticsList_01List. jsp?vwcd=MT_ETITLE\&parentId=B\#SubCont. Accessed May 17, 2018.

2. Korean Statistical Information Service. Unemployment Rate, Annual 2005-2016. Available at: http://kosis.kr/eng/statisticsList/statisticsList_ 01List.jsp?vwcd=MT_ETITLE\&parentId=B\#SubCont. Accessed June 01, 2018.

3. Chang SS, Gunnell D, Sterne JA, Lu TH, Cheng AT. Was the economic crisis 1997-1998 responsible for rising suicide rates in East/Southeast Asia? A time-trend analysis for Japan, Hong Kong, South Korea, Taiwan, Singapore and Thailand. Soc Sci Med 2009;68:1322-1331.

4. Jang SA, Sung JM, Park JY, Jeon WT. Copycat suicide induced by entertainment celebrity suicides in South Korea. Psychiatry Investig 2016;13:74-81.

5. Hong J, Knapp M. Impact of macro-level socio-economic factors on rising suicide rates in South Korea: panel-data analysis in East Asia. J Ment Health Policy Econ 2014;17:151-162.

6. Yip PSF, Law CK, Fu KW, Law YW, Wong PW, Xu Y. Restricting the means of suicide by charcoal burning. Br J Psychiatry 2010;196:241242.

7. Chen YY, Chen F, Chang SS, Wong J, Yip PS. Assessing the efficacy of restricting access to barbecue charcoal for suicide prevention in Taiwan: a community-based intervention trial. PLoS One 2015;10:e0133809.

8. Gyeonggi Provincial Center for Suicide Prevention. The Guidebook for Charcoal-Selling Procedure Improvement Campaign. Suwon: Gyeonggi Provincial Center for Suicide Prevention of Korea; 2015.

9. McCleary R, Hay R. Applied Time Series Analysis. Beverly Hills: Sage; 1980.

10. Lütkepohl H. New Introduction to Multiple Time Series Analysis. New York: Springer-Verlag Berlin Heidelberg; 2005.

11. Korean Statistical Information Service. Population Statistics Based on Resident Registration, 2017. Available at: http://kosis.kr/eng/statisticsList/statisticsList_01List.jsp?vwcd=MT_ETITLE\&parentId=B\#SubCont. Accessed April 15, 2018.

12. World Health Organization. The tenth revision of the International Classification of Diseases codes, Ver.2010. Available at: http://apps.who. int/classifications/icd10/browse/2010/en\#/X67. Accessed April 15, 2018.

13. Korean Statistical Information Service. Cause of Death, Annual 20002016. Available at: http://kosis.kr/eng/statisticsList/statisticsList_01List. jsp?vwcd=MT_ETITLE\&parentId=B\#SubCont. Accessed May 10, 2018.

14. Lee T, Lee AR, Ahn MH, Jeong SY, Hong JP. Overview of suicide by charcoal burning and prevention strategies. J Korean Neuropsychiatr Assoc 2014;53:1-7.

15. Janoski T, Isaac LW. The Comparative Political Economy of the Welfare State. In: Janoski T, Kicks AM, Editors. Introduction to Time-Series Analysis. New York: Cambridge University Press, 1994, p.31-53.

16. Korean Statistical Information Service. Population, Annual 2001-2016. Available at: http://kosis.kr/statHtml/statHtml.do?orgId=210\&tblid=D T_21002B004\&conn_path=I3. Accessed Oct 10, 2018.

17. Mann JJ, Apter A, Bertolote J, Beautrais A, Currier D, Haas A, et al. Suicide prevention strategies: a systematic review. JAMA 2005;294: 2064-2074.

18. Chan SS, Chiu HF, Chen EY, Chan WS, Wong PW, Chan CL, et al. What does psychological autopsy study tell us about charcoal burning suicide- a new and contagious method in Asia? Suicide Life Threat Behav 2009;39:633-638.

19. Pan YJ, Liao SC, Lee MB. Suicide by charcoal burning inTaiwan, 19952006. J Affect Disord 2010;120:254-257. 